\title{
Calibration of partial safety factors according to Eurocodes
}

\author{
Peter Koteš $\check{~}^{1, *}$, Jozef Prokop ${ }^{1}$, Miroslav Strieška ${ }^{1}$, and Josef Vičan ${ }^{1}$ \\ ${ }^{1}$ University of Žilina, Faculty of civil engineering, Univerzitná 8215/1, 01026 Žilina, Slovakia
}

\begin{abstract}
Recommended reliability levels and their adequate partial safety factors can be found in Eurocodes only for design of new structures and bridges. Modified reliability levels and partial safety factors for verifying bridge structures for their remaining lifetime were determined by theory of reliability at Department of Structures and Bridges at Civil Engineering Faculty, University of Žilina. This paper is focused on verification of modified partial safety factors of materials and load effects using calibration.
\end{abstract}

\section{Introduction}

Each building and civil engineer should ensure that the design of the building and civil structures is reliable, in this case the reliability of the bridge structures. The reliability is the ability of the construction to perform the required functions to which it was designed under normal conditions and maintenance without any necessary repairs and reconstructions throughout its design lifetime $T_{\mathrm{d}}$.

For newly designed structures, the decisive role of the properties, as load-bearing capacity, safety, serviceability, durability and robustness, which are closely related to each other, are crucial to ensuring the required reliability. We consider the probability of failurefree operation during the operation, which is also called as the reliability level and is denoted as $\mathrm{P}_{\mathrm{r}}$. The opposite value of the reliability level is the failure probability $\mathrm{P}_{\mathrm{f}}$ and it expresses the probability of occurrence of a failure over the lifetime of the structure and the following should valid

$$
P_{r}=1-P_{f} .
$$

Any building construction is not completely safe and reliable, because its resistance and load are affected by uncertainties that can be of different character.

\section{Existing bridge structures - calibration of partial safety factors}

The partial safety factors for the design of new bridge structures are given in codes [1-5]. The standards are an important part in designing new bridge structures, but also in

* Corresponding author: kotes@,fstav.uniza.sk 
evaluating existing bridges. The actions of bridges according to the code [1] are defined by a representative (e.g. characteristic) value and the partial safety factors for loads. This standard also defines load combinations. However, these partial safety factors can be used only for the design of new bridge structure for the whole design lifetime $T_{d}=100$ years, but not for the evaluation of existing bridge structure for their remaining lifetime $t_{r}$. The modified reliability levels given by the reliability index $\beta_{t}$ or by the probability of failure $\mathrm{P}_{\mathrm{ft}}$ and the corresponding partial safety factors of material properties and load effects were determined in the frame of the research activities of the Department of Structures and Bridges of University of Žilina [6, 7, 8]. The recommended modified reliability levels for the planned remaining lifetime of the bridge structures in the simplified form are shown in Tab. 1 .

Table 1. Modified values of reliability index $\beta_{\mathrm{t}}$ and the probability of failure $\mathrm{P}_{\mathrm{ft}}$ for remaining lifetime.

\begin{tabular}{|c|c|c|c|c|c|c|}
\hline \multirow{2}{*}{$\begin{array}{c}\text { Planned remaining lifetime } \\
\mathbf{t}_{\mathbf{r}} \text { [years] }\end{array}$} & \multicolumn{6}{|c|}{ Inspection in time - age of the bridge structure/member } \\
\cline { 2 - 8 } & \multicolumn{2}{|c|}{$\mathbf{4 0}$ years } & \multicolumn{2}{|c|}{$\mathbf{6 0}$ years } & \multicolumn{2}{|c|}{$\mathbf{7 0}$ years } \\
\cline { 2 - 7 } & $\boldsymbol{\beta}_{\mathbf{t}}$ & $\mathbf{P}_{\mathbf{f t}}$ & $\boldsymbol{\beta}_{\mathbf{t}}$ & $\mathbf{P}_{\mathbf{f t}}$ & $\boldsymbol{\beta}_{\mathbf{t}}$ & $\mathbf{P}_{\mathbf{f t}}$ \\
\hline$<2$ & 2.767 & $2.830 \cdot 10^{-3}$ & 2.632 & $4.248 \cdot 10^{-3}$ & 2.578 & $4.975 \cdot 10^{-3}$ \\
\hline $2-10$ & 3.209 & $6.666 \cdot 10^{-4}$ & 3.108 & $9.439 \cdot 10^{-4}$ & 3.066 & $1.085 \cdot 10^{-3}$ \\
\hline $10-20$ & 3.354 & $3.984 \cdot 10^{-4}$ & 3.271 & $5.362 \cdot 10^{-4}$ & 3.236 & $6.061 \cdot 10^{-4}$ \\
\hline$>20$ & 3.424 & $3.093 \cdot 10^{-4}$ & 3.352 & $4.012 \cdot 10^{-4}$ & 3.322 & $4.477 \cdot 10^{-4}$ \\
\hline
\end{tabular}

\subsection{Partial safety factors of loads effects}

Individual loads are considered as random variables and they are described by the coefficient of variation $\mathrm{v}$ and the bias factor $\lambda$, which expresses the ratio between the mean value and the characteristic value $[9,10]$. The modified reliability levels for the evaluation of existing bridge structures affect the modified values of the partial safety factors of the load effects and material properties. For this calculation, it is necessary to know the characteristics of the statistical distributions of individual loads, as the distribution functions, density functions, mean values, standard deviations, etc.

\subsubsection{Permanent load effects}

The mean value $m_{G}$ is the characteristic value $G_{k}$ of permanent load if the coefficient of variation is $\mathrm{v}_{\mathrm{G}} \leq 0.10$ (normally ranging in $\mathrm{v}_{\mathrm{G}}=0.02 \sim 0.05$ ). Permanent loads of bridge structures include the self-weight of structural and non-structural members of the structures. According to Amendment A1 of Annex A2 [11] of Standard [3], two values for the partial safety factors for permanent loads of the structural and non-structural members of the bridges are recommended, depending on whether they are factory-made products $\left(\gamma_{\mathrm{G}}=\right.$ $1.25)$, or they are cast-in-place products $\left(\gamma_{\mathrm{G}}=1.35\right)$ due to possible different variations in the weights of the structural elements.

When considering the normal distribution of random variables of constant loads, then the partial safety factor is given by the equation

$$
\gamma_{G, i}=\gamma_{S d} \cdot \frac{G_{d}}{G_{k}}=\gamma_{S d} \cdot \frac{m_{G, i} \cdot\left(1+\alpha_{E} \cdot \beta_{t} \cdot v_{G, i}\right)}{m_{G, i}},
$$


where $\quad G_{d} \quad$ is the design value of permanent load,

$\mathrm{G}_{\mathrm{k}} \quad$ is the characteristic value of permanent load,

$\mathrm{m}_{\mathrm{G}, \mathrm{i}} \quad$ is the mean value of each permanent loads,

$\mathrm{v}_{\mathrm{G}, \mathrm{i}} \quad$ is the coefficient of variation of each permanent loads,

$\gamma_{\mathrm{Sd}}=1.05$ is the partial safety factor for model uncertainties,

$\alpha=0.70$ is the sensitivity coefficient of the load,

$\beta_{\mathrm{t}} \quad$ is the modified value of the reliability index for evaluation (Tab. 1).

The recommended modified partial safety factors of the factory-made products are given in Tab. 2. These include, for example, bridge rails, guard-rails, vehicle parapets, waterproofing (asphalt) and prefabricated parts of the superstructure.

Table 2. Partial safety factors of permanent loads - factory-made products (basic value $\gamma_{\mathrm{G}}=1.25$ )

\begin{tabular}{|c|c|c|}
\hline Planned remaining lifetime & \multicolumn{2}{|c|}{$\boldsymbol{\gamma}_{\mathbf{G}, \mathbf{i}}$ for age of the bridge structure/member } \\
\cline { 2 - 3 } $\mathbf{t}_{\mathbf{r}}$ [years] & $\leq \mathbf{6 0}$ years & $>\mathbf{6 0}$ years \\
\hline$\leq 2$ & 1.20 & 1.20 \\
\hline $2-10$ & 1.25 & 1.20 \\
\hline$>10$ & 1.25 & 1.20 \\
\hline
\end{tabular}

The recommended modified partial safety factors of the permanent loads of the elements cast-in-place in relation to the planned remaining lifetime of the bridge are given in Tab. 3. These loads include the actual weight of the monolithic parts of the superstructures, the pavement, the ballast bed, and the like.

Table 3. Partial safety factors of permanent loads - cast-in-place products (basic value $\gamma_{\mathrm{G}}=1.35$ )

\begin{tabular}{|c|c|c|}
\hline Planned remaining lifetime & \multicolumn{2}{|c|}{$\boldsymbol{\gamma}_{\mathbf{G}, \mathbf{i}}$ for age of the bridge structure/member } \\
\cline { 2 - 3 } $\mathbf{t}_{\mathbf{r}}$ [years] & $\mathbf{5 6 0}$ years & $>\mathbf{6 0}$ years \\
\hline$\leq 2$ & 1.30 & 1.25 \\
\hline $2-10$ & 1.30 & 1.30 \\
\hline$>10$ & 1.35 & 1.30 \\
\hline
\end{tabular}

\subsubsection{Variable load effects}

Variable loads (traffic loads) on road bridges are given in code [1] by load models LM1 to LM4. For the calibration of bridge constructions, two decisive load models were considered:

- LM1, given by three-lane concentric axle loads and a continuous equivalent load, which represent most of the effects of normal traffic,

- LM3, which is given by a grouping of axle loads representing the special vehicles that can travel along the routes.

The decisive load model was considered from two of those that had greater unfair effects on the structure (LM1 or LM3). The variable load effects (traffic loads on road bridges) are random variables with a Gumbel's distribution [3]. For this reasoning, the partial safety factors of the variable load effects is defined by the relation

$$
\gamma_{Q}=\gamma_{S d} \cdot \frac{Q_{d}}{Q_{k}}=\gamma_{S d} \cdot \frac{m_{Q} \cdot\left(1-v_{Q}\left[0,449+0,778 \cdot \ln \left(-\ln \Phi\left(\alpha_{E} \cdot \beta_{t}\right)\right)\right]\right)}{m_{Q} \cdot\left(1-v_{Q}[0,449+0,778 \cdot \ln (-\ln (0,95))]\right)}
$$

$\mathrm{Q}_{\mathrm{k}} \quad$ is the characteristic value of variable load effects,

$\mathrm{m}_{\mathrm{Q}} \quad$ is the mean value of variable load effects, 
$\mathrm{v}_{\mathrm{Q}} \quad$ is the coefficient of variation of variable load effects,

$\Phi \quad$ is the distribution function of random variable.

The recommended modified partial safety factors of the variable load effects taken into account the planned remaining lifetime of the bridge are given in Tab. 4.

Table 4. Partial safety factors of variable load effects (basic value $\gamma_{\mathrm{Q}}=1.35$ )

\begin{tabular}{|c|c|c|}
\hline Planned remaining lifetime & \multicolumn{2}{|c|}{$\boldsymbol{\gamma}_{\mathbf{G}, \mathbf{i}}$ for age of the bridge structure/member } \\
\cline { 2 - 3 } $\mathbf{t}_{\mathbf{r}}$ [years] & $\leq \mathbf{6 0}$ years & $>\mathbf{6 0}$ years \\
\hline$\leq 2$ & 1.15 & 1.10 \\
\hline $2-10$ & 1.25 & 1.20 \\
\hline$>10$ & 1.30 & 1.20 \\
\hline
\end{tabular}

\subsection{Calibration - theoretical approach}

Verification of reliability is based on limit states that represent the boundary between reliability and failure of structure/member. The paper focuses on the ultimate limit state bending resistance. In principle, we always try to find a design point that we consider to be the limit of failure. In this case, the Rackwitz-Fiessler iterative method was applied, which was also used to calibrate the partial safety factors for loads and material resistance for the American and Canadian standards $[9,10]$. The design point lies at the failure boundary and shows the greatest probability of failure, the failure boundary being given by equation

$$
M=R-E,
$$

for the design point $D\left(R_{D}, E_{D}\right)$ is valid $R_{D}=E_{D}$.

$F_{R}$ is the cumulative distribution function and $f_{R}$ is the probability density function for R. Similarly, $F_{E}$ and $f_{E}$ are valid for load effects. Firstly, an initial value of design point $R_{D}$ is guessed. The method assumes approximation of cumulative distribution function $F_{R}$ and $\mathrm{F}_{\mathrm{E}}$ on normal distribution function $\overline{F_{R}}, \overline{F_{E}}$. Then, the standard deviation and the mean value of $R_{D}$ are

$$
\begin{gathered}
\overline{\sigma_{R}}=\varphi_{n}\left\{\phi^{-1}\left[F_{R}\left(R_{D}\right)\right]\right\} / f_{R}\left(R_{D}\right), \\
\overline{\mu_{R}}=\overline{R_{D}}-\overline{\sigma_{R}} \cdot \phi^{-1}\left[F_{R}\left(R_{D}\right)\right],
\end{gathered}
$$

where $\phi \quad$ is distribution function of the standard normal distribution,

$\varphi_{\mathrm{n}} \quad$ is density function of standard normal random variable.

Similarly, the same formulas can be derived for $\overline{\mu_{E}}$ and $\overline{\sigma_{E}}$ of the load effects

$$
\begin{gathered}
\overline{\sigma_{E}}=\varphi_{n}\left\{\phi^{-1}\left[F_{E}\left(R_{E}\right)\right]\right\} / f_{E}\left(R_{E}\right), \\
\overline{\mu_{E}}=\overline{R_{E}}-\overline{\sigma_{E}} \cdot \phi^{-1}\left[F_{E}\left(R_{E}\right)\right] .
\end{gathered}
$$

It is now possible to determine the reliability index $\beta$, which defines the distance of the design point $\mathrm{D}$ from the beginning in shape

$$
\beta=\left(\overline{\mu_{R}}-\overline{\mu_{E}}\right) /\left(\left(\overline{\sigma_{R}}\right)^{2}+\left(\overline{\sigma_{E}}\right)^{2}\right)^{0,5} .
$$


Next, a new design point can be calculated from the following equations

$$
\begin{aligned}
& R_{D}=\overline{\mu_{R}}-\beta \cdot\left(\overline{\sigma_{R}}\right)^{2} /\left(\left(\overline{\sigma_{R}}\right)^{2}+\left(\overline{\sigma_{E}}\right)^{2}\right)^{0,5}, \\
& E_{D}=\overline{\mu_{E}}-\beta \cdot\left(\overline{\sigma_{E}}\right)^{2} /\left(\left(\overline{\sigma_{R}}\right)^{2}+\left(\overline{\sigma_{E}}\right)^{2}\right)^{0,5} .
\end{aligned}
$$

So, the second iteration can begin. The approximating normal distributions are found for $F_{R}$ and $F_{E}$ at the new design point. The reliability index was calculated using formula (9) and the next design point is found from (10) and (11). Approximation is continued until $R_{D}$ and $\mathrm{E}_{\mathrm{D}}$ do not change in consecutive iterations. In our case of calibration, the resistance of reinforced concrete girders was assumed as lognormal random variable and the load effects were assumed as normal random variables. From this reason, it is not needed to do their approximation.

The design reliability levels, which are projected into partial safety factors, were calibrated on reinforced concrete bridges, three slabs and one frame bridge. These are already existing bridge structures near town Nitra.

The calibration was performed on the basis of the actual traffic load, which was determined by the traffic count in 2010 by the Slovak Road Administration (SRA). The maximal positive moments in the middle of the span, respectively, at the point of maximum positive moments, if they are not in the middle of the span, were considered as the load effects for calibration.

Calculation of load effects from individual load models was performed in programme SCIA Engineer on slab models. The real traffic loads on the bridge was simulated by passage cars for 5 standard categories of vehicles N1, N2, N3, PN3 and NS.

Since the actual age of the selected bridge constructions was not known exactly, the calibration was performed on the assumption that they were less than 60 years of age and equal to or greater than 60 years and compared the residual life for both cases.

A frame bridge was also included in the set of bridges. Specifically, these are objects no. 51-124 at the village of Babindol, no. 65-012 near the village Tesare, no. 51-134 in the village of Čifáre and no. 51-125 at the village Klasov. The brief characteristics of the individual bridges are:

- Object no. 51-124 at the village of Babindol - it is a single span slab bridge with a span of $2.30 \mathrm{~m}$. The width of the road on the bridge is $8.24 \mathrm{~m}$.

- Object no. 65-012 near the village of Tesare - it is a single span slab structure with a span of $13.60 \mathrm{~m}$. The width of the road on the bridge is $10.30 \mathrm{~m}$.

- Object no. 51-134 in the village of Čifáre - it is a single span slab structure with a span of $4.30 \mathrm{~m}$ (total length is $4.60 \mathrm{~m}$ ). The width of the road to the bridge is $7.80 \mathrm{~m}$.

- Object no. 51-125 at the village of Klasov - it is a single span frame structure with a span of $4.45 \mathrm{~m}$ and a height of $2.80 \mathrm{~m}$. The width of the road on the bridge is $7.90 \mathrm{~m}$.

This approach should take into account the actual parameters of the bridge objects as well as the possible degradation of the materials [14-18], eventually the possible fatigue failure $[19,20]$. For this reason, diagnostics were first performed on the bridge objects. Diagnostic results were included in bridged objects models - measured geometric and material properties with regard to failures. As the observed support element was considered the most stressed part of the slab width of $1.0 \mathrm{~m}$. The bridge slabs were modelled as slabs.

Due to the character of the reinforced concrete, the cross-section resistances were considered as random variables with normal distribution. In the partial safety factor method, for the basic load combination with one variable short-term load, the equation for the element subjected to bending is 


$$
\gamma_{G, 1} \cdot M_{G 1, k}+\gamma_{G, 2} \cdot M_{G 2, k}+\gamma_{F, t} \cdot \delta \cdot M_{t, k} \leq M_{k} / \gamma_{M, c},
$$

kde $\gamma_{\mathrm{G}, 1}$ is the partial safety factor for cast-in-place products - permanent load,

$\gamma_{\mathrm{G}, 2}$ is the partial safety factor for factory-made products - permanent load,

$\gamma_{\mathrm{F}, \mathrm{t}}$ is the partial safety factor for variable loads,

$\gamma_{\mathrm{M}, \mathrm{c}}$ is the partial safety factor for reinforced concrete material,

$\mathrm{M}_{\mathrm{Gi}, \mathrm{k}}$ are the characteristic values of bending moments due to permanent loads,

$\mathrm{M}_{\mathrm{t}, \mathrm{k}}$ is the characteristic values of bending moments due to variable loads,

$\mathrm{M}_{\mathrm{k}}$ is the characteristic values of bending resistance,

$\delta \quad$ is the dynamic coefficient, in the case of road bridges is equal to 1.0.

The partial safety factor for material for reinforced concrete element subjected to bending $\gamma_{\mathrm{M}, \mathrm{c}}$ as a whole cross-section includes the individual partial safety factors of the concrete for compression $\gamma_{\mathrm{c}, \mathrm{c}}$ and the reinforcement $\gamma_{\mathrm{s}}$. For this reason, the partial safety factor was obtained from the ration between the characteristic moment of resistance of the reinforced concrete cross-section $\mathrm{M}_{\mathrm{k}}$ and the design moment of resistance of the same cross-section $\mathrm{M}_{\mathrm{d}}$ calculated according to the standard [5]

$$
\gamma_{M, c} \leq M_{k} / M_{d}
$$

Since the reliability index has been calculated for several possible remaining lifetimes, it was also necessary to calculate the material reliability factor $\gamma_{\mathrm{M}, \mathrm{c}}$ for each of them. The resulting material reliability factors for slab bridges can be found in Tab. 5. In order to calculate the reliability indices, it was also necessary to determine the statistical characteristics of the load effects for each bridge object separately, namely the mean value $\mu_{\mathrm{E}}$ and the standard deviation $\sigma_{\mathrm{E}}$. Actual traffic data on selected bridges has been provided to us by the Slovak Road Administration. The resulting reliability index values for slab bridges are shown in Tab. 6.

When comparing calculated reliability indices with modified reliability indices according to $[6,7,8]$, we find that they are much higher. This means that the selected slab bridges are suitable for a remaining lifetime of at least 20 years.

Table 5. Partial safety factors of materials for slab bridges

\begin{tabular}{|c|c|c|c|}
\hline \multirow{2}{*}{$\begin{array}{c}\text { Bridge structure } / \text { Planned } \\
\text { remaining lifetime } \mathbf{t}_{\mathbf{r}} \text { [years] }\end{array}$} & \multicolumn{2}{|c|}{$\boldsymbol{\gamma}_{\mathbf{M}, \mathbf{c}}$} \\
\cline { 2 - 4 } & age of the bridge $\leq \mathbf{6 0}$ years & age of the bridge $>$ 60 years \\
\hline n. 51-124 & $>20$ & 1.167 & 1.117 \\
\cline { 2 - 4 } & $10<\mathrm{t}_{\mathrm{r}} \leq 20$ & 1.164 & 1.114 \\
\cline { 2 - 4 } & $2<\mathrm{t}_{\mathrm{r}} \leq 10$ & 1.114 & 1.111 \\
\cline { 2 - 4 } & $\leq 2$ & 1.106 & 1.056 \\
\hline \multirow{3}{*}{ Babind 51-125 } & $>20$ & 1.155 & 1.105 \\
\cline { 2 - 4 } & $10<\mathrm{t}_{\mathrm{r}} \leq 20$ & 1.154 & 1.104 \\
\cline { 2 - 4 } & $2<\mathrm{t}_{\mathrm{r}} \leq 10$ & 1.104 & 1.103 \\
\cline { 2 - 4 } & $\leq 2$ & 1.102 & 1.052 \\
\hline \multirow{3}{*}{ n. 51-134 } & $>20$ & 1.176 & 1.126 \\
\cline { 2 - 4 } & $10<\mathrm{t}_{\mathrm{r}} \leq 20$ & 1.172 & 1.122 \\
\cline { 2 - 4 } & $2<\mathrm{t}_{\mathrm{r}} \leq 10$ & 1.122 & 1.117 \\
\cline { 2 - 4 } & $\leq 2$ & 1.109 & 1.059 \\
\hline \multirow{3}{*}{ n. 65-012 } & $>20$ & 1.202 & 1.152 \\
\cline { 2 - 4 } & $10<\mathrm{t}_{\mathrm{r}} \leq 20$ & 1.193 & 1.143 \\
\cline { 2 - 4 } & $2<\mathrm{t}_{\mathrm{r}} \leq 10$ & 1.143 & 1.134 \\
\cline { 2 - 4 } & $\leq 2$ & 1.117 & 1.067 \\
\hline
\end{tabular}


Table 6. Values of reliability indices $\beta$ for remaining lifetime on slab bridges

\begin{tabular}{|c|c|c|c|c|c|c|c|c|}
\hline \multirow{3}{*}{$\begin{array}{c}\text { Bridge } \\
\text { structure }\end{array}$} & \multicolumn{4}{|c|}{ Age of the bridge $\leq 60$ years } & \multicolumn{4}{|c|}{ Age of the bridge $>60$ years } \\
\hline & \multicolumn{4}{|c|}{ Planned remaining lifetime $t_{r}$ [years] } & \multicolumn{4}{|c|}{ Planned remaining lifetime $t_{r}$ [years] } \\
\hline & $\leq 2$ & $2<t_{r} \leq 10$ & $10<t_{r} \leq 20$ & $>\mathbf{2 0}$ & $\leq 2$ & $2<t_{r} \leq 10$ & $10<t_{r} \leq 20$ & $>\mathbf{2 0}$ \\
\hline $\begin{array}{l}\text { n. 51-124 } \\
\text { Babindol }\end{array}$ & 8.166 & 8.364 & 8.566 & 8.571 & 7.897 & 8.272 & 8.279 & 8.086 \\
\hline $\begin{array}{c}\text { n. } 51-125 \\
\text { Klasov }\end{array}$ & 6.770 & 6.888 & 7.024 & 7.025 & 6.590 & 6.832 & 6.833 & 6.834 \\
\hline $\begin{array}{l}\text { n. } 51-134 \\
\text { Čifáre }\end{array}$ & 8.717 & 8.960 & 9.203 & 9.213 & 8.403 & 8.849 & 8.862 & 8.874 \\
\hline $\begin{array}{l}\text { n. } 65-012 \\
\text { Tesáre }\end{array}$ & 7.579 & 7.962 & 8.437 & 8.480 & 7.053 & 7.794 & 7.840 & 7.887 \\
\hline $\begin{array}{l}\text { Recomm. } \\
\text { value }\end{array}$ & 2.632 & 3.108 & 3.271 & 3.352 & 2.578 & 3.066 & 3.236 & 3.322 \\
\hline
\end{tabular}

\section{Conclusions}

In the paper, modified reliability levels and partial safety factors of load effects and reliability of materials on existing reinforced concrete slab bridges (one bridge object was frame structure) were verified by means of calibration. From the calculated reliability indices, we can see that all observed slab bridges have a significantly higher level of reliability than the recommended values. This means that even if they do not know their true age, they are still suitable for the remaining lifetime (up to and over 20 years).

Furthermore, it is possible to observe from this statistical set that the reliability level is much higher than the recommended values for most bridge objects. This means that the load given in codes is far greater than the actual load that occurs on road communications. If the same assumption were to be found with a larger number of bridge structures, it would be worthwhile to reduce the given load in the design of new constructions by the categorization coefficients $\alpha_{\mathrm{q}}$ and $\alpha_{\mathrm{Q}}$, which could result in economically more efficient design of bridge structures on road communications. This would, however, need to make a recalculation on a substantially larger set of different types of bridge objects.

The paper presents results of the research project APVV-14-0772 supported by the Slovak Research and Development Agency, the project 012ŽU-4/2016 supported by the Cultural and Education Agency of Slovak Republic, by the European Regional Development Fund and the Slovak state budget for the project "Research Centre of University of Žilina" ITMS 26220220183 and by Research Project No. 1/0566/15 of Slovak Grant Agency

\section{References}

1. STN EN 1991-2 (73 6203): Eurocode 1. Actions on structures. Part 2: Traffic loads on bridges. SÚTN (2006) (in Slovak)

2. STN EN 1991-1-1 (73 0035): Eurocode 1. Actions on structures. Part 1-1: General actions - Densities, self-weight, imposed loads for buildings. SÚTN (2007) (in Slovak)

3. STN EN 1990 (73 0031): Eurocode. Basis of structural design. SÚTN (2009) (in Slovak)

4. STN EN 1992-1-1 (73 1201): Eurocode 2. Design of concrete structures. Part 1-1: General rules and rules for buildings. SÚTN (2007) (in Slovak) 
5. STN EN 1992-2 (73 6206): Eurocode 2. Design of concrete structures. Part 2: Concrete bridges - Design and detailing rules. SÚTN (2007) (in Slovak)

6. Koteš, P., Reliability of existing bridge structures and possibilities of its increasing. Habilitation thesis, Žilina, 143 p. (2012) (in Slovak)

7. Koteš, P., Vičan, J., Reliability-based evaluation of existing concrete bridges in Slovakia according to Eurocodes. In: The Fourth International fib Congress 2014, Mumbai, „Improving Performance of Concrete Structures“, Proceedings, Mumbai, India, 2014, (C) IMC-FIB, pp. 227-229 (2014)

8. Koteš, P. - Vičan, J., Recommended reliability levels for the evaluation of existing bridges according to eurocodes. In: Structural Engineering International International Association for Bridge and Structural Engineering (IABSE), SEI Volume 23, 4, p. 411-417 (2013)

9. Nowak, A.S., Calibration of LFRD Bridge Code. In: Journal of Structural Enfineering, pp. 1245-1251 (1995)

10. Nowak,A.S., Grouni, H.N., Calibration of the Ontario Highway Bridge Code 1991 edition. In: Canadian Journal of Ci. Engineering 21, pp. 25-35 (1994)

11. STN EN 1990 (73 0031): (in Slovak). Basis of structural design. Amendment A1. Annex A2: Use for bridges. SÚTN (2006) (in Slovak)

12. Benko, V.: Reliability of structures (according to Eurocodes). SKSI, 86. P, (2010)

13. Bilčík, J., Fillo, L., Benko, V., Halvoník, J., Concrete structures. Design according to STN EN 1992-1-1. Editorship STU in Bratislava, 374 p. (2008)

14. Macho, M., Ryjaček, P., The impact of the severe corrosion on the structural behavior of steel bridge members. Advances and Trends in Engineering Sciences and Technologies - Proceedings of the International Conference on Engineering Sciences and Technologies, ESaT 2015, pp. 123-128 (2015)

15. Ryjaček, P., Macho, M., Stančík, V., Polák, M., The Deterioration and assessment of steel bridges. Maintenance, Monitoring, Safety, Risk and Resilience of Bridges and Bridge Networks - Proceedings of the 8th International Conference on Bridge Maintenance, Safety and Management, IABMAS 2016, pp. 1188-1195 (2016)

16. Hollý, I., Bilčík, J., Gajdošová, K., Numerical modeling of reinforcement corrosion on bond behaviour. International Multidisciplinary Scientific GeoConference Surveying Geology and Mining Ecology Management, SGEM, 249, pp. 191-196 (2016)

17. Paulík, P., Bačuvčík, M., Ševčík, P., Janotka, I., Gajdošová, K., Experimental evaluation of properties of 120 years old concretes at two concrete bridges in Slovakia. International Multidisciplinary Scientific GeoConference Surveying Geology and Mining Ecology Management, SGEM, 249, pp. 227-234 (2016)

18. Kala, V., Valeš, J., Stochastic analysis of the lateral beam buckling of beams with initial imperfections. Safety and Reliability of Complex Engineered Systems Proceedings of the 25th European Safety and Reliability Conference, ESREL 2015, pp. 2547-2552 (2015)

19. Krejsa, M., Koubova, L., Flodr, J., Protivinsky, J., Nguyen, Q.T., Probabilistic prediction of fatigue damage based on linear fracture mechanics. Frattura ed Integrita Strutturale, 11, Issue 39, Volume 249, pp. 143-159 (2017)

20. Krejsa, M., Probabilistic reliability assessment of steel structures exposed to fatigue. Safety, Reliability and Risk Analysis: Beyond the Horizon - Proceedings of the European Safety and Reliability Conference, ESREL 2013, pp. 2671-2679 (2013) 